\title{
correspondence
}

\section{Closure in Belgium?}

SIR,-DDe to a political decision, a research institute I head is about to be closed (Institut de Recherche Interdisciplinaire en Biologie Humaine et Nucléaire) and another to be severely handicapped (Département de Biologie Moléculaire, under Professor $\mathrm{J}$. Brachet) at the University of Brussels. In a European country where the stability of employment is high and the turnover rate of personnel very low, this situation is highly unusual.

The Institute was created in 1963 to develop, in connection with clinical research units and with a sister group in Pisa (Italy), the use of radioisotopes in medical research and medicine. Since then, it has slowly evolved into what is now the Institut de Recherche Interdisciplinaire of the Université Libre de Bruxelles, a lab where physicists, chemists, biologists and MDs collaborate in biomedical research on many subjects (thyroid metabolism, cancer, cyclic nucleotides, lung physiology, theoretical biology, etc.).

Since its creation, the group has been subsidised by Euratom and the Universities of Brussels and Pisa. In 1969, Belgium did not participate any more in the Euratom programme of Nuclear Medicine. At that time, the government decided to support and create new research groups, "Actions Concertées", in the universities which would, like the Medical Research Council research units in Great Britain and the National Institutes of Health clinical research centres in the US, be catalysts for university research. This has worked well since then. The groups of Brussels were the first to be created and thus the first to arrive at the end of their five year contract.

This year, the government developed a new framework for research in which the whole structure of Belgian research is changed. This project has been criticised. One of its features is the concept of subsidising university research in proportion to the number of students. The government has agreed that the groups would fit in well in this new programme, but it has tied the granting of finance to the "Actions Concertées" to the approval of its programme. As the new project is now delayed, and as the contract is coming to its end, no financial support is planned for 1976. Thus the group is now, because of a political squabble, left "in the air".
Most of the permanent staff was not paid at the end of December. Thus in a few weeks the group might be disbanded. This situation has been much discussed in the Belgian press. The Minister insists that the Universities should take over temporarily, but the hard pressed university is financially and legally unable to do it. It is already badly burnt by a new "loi-programme" on finances, which includes a new subsidisation scheme for universities and which caused much turmoil and student demonstrations in the country in 1975 .

Yours faithfully,

(Professor) J. E. Dumont

Institut de Recherche Interdisciplinaire en Biologie Humaine et Nucléaire, Université Libre de Bruxelles, Belgium

\section{Crisis in Italian universities}

SIR,-I was impressed by the objectivity and completeness of Gillian Boucher's article (November 20, page 190). The causes of the Italian university crisis do not require further elucidation, still less comments like those of Giacomo Morpurgo (December 11, page 475). Morpurgo's letter, if published in an Italian magazine and not in an authoritative and widely circulated scientific journal such as Nature, would not deserve mention. His statements are ridiculous and untrue.

It is absurd to assert that the "intended aim" of the recent laws was to assure a permanent position for a large number of leftists "disposed to aggressive political activity". Morpurgo knows that these laws were promulgated by a Christian Democrat government which has ruled the country for thirty years.

After the results of the June 15 elections nobody should be surprised that the majority of university teachers are left wing. The intellectual class in Italy (with the exception of a few people like Morpurgo) was leftist long before June 15.

It is true that departments are invaded less frequently now than a few years ago. But this phenomenon is not confined to Italy. In every country student dissent is weaker than it was in 1968 , for reasons much more serious than those invented by Morpurgo.

The recent laws have given tenure to a large number of university teachers and researchers whose positions had been precarious for a long time pre- viously. The laws have repaired old injustices. If many teachers do not deserve their present positions, that is the fault of the University "baroni" who, by keeping their staff in menial positions for their own convenience, have given them the right to exploit the new laws. One of the privileges of the full professors was to create whatever positions they wanted and to assign them to whoever they liked for as long as they liked. If today the Department of Physics in the University of Genoa has more teachers than students, that, too, is the fault of Professor Morpurgo and his colleagues.
Yours faithfully,
Francesco Ghiretti
Anna GhiretTi-Magilidi

Institute of Animal Biology,

University of Padua, Italy

\section{Water to the Dead Sea}

SIR, - While it would be possible to generate electric power (November 6, page 9) from the flow of seawater into any depression lying below sea level-the Dead Sea (surface at $-390 \mathrm{~m}$ ), the Qattara Depression $(-138 \mathrm{~m})$, or possibly even the Caspian Sea $(-28 \mathrm{~m})$-there is one thermodynamic possibility that applies to the Dead Sea alone. It is possible to deliver fresh water to the valley of the Dead Sea by a spontaneous process using a system with no moving parts.

The osmotic pressure of seawater is about 25 bar, and this pressure is reached with a head of $250 \mathrm{~m}$ of water. Any greater pressure would cause fresh water to flow through an osmotic membrane such as those used for desalination by reverse osmosis. Fresh water could be delivered to the valley of the Dead Sea not much below $-250 \mathrm{~m}$. This water could then be used to irrigate a substantial area, particularly around the mouth of the Jordan River.

To use the flow of seawater into the Dead Sea exclusively for the generation of electric power is to neglect that what the desert most needs is fresh water. There is no reason, however, why the two projects cannot be combined, with fresh water being obtained at negligible added capital cost over that for electric power alone.

$$
\begin{aligned}
& \text { Yours faithfully, } \\
& \text { G. S. KEI.T } \\
& \text { Y. LUPIEN }
\end{aligned}
$$

National Research Council,

Ottawa, Canada 